\title{
Composição corporal e requisitos energéticos de bovinos de corte sob suplementação em pastejo ${ }^{1}$
}

\section{Maykel Franklin Lima Sales ${ }^{2}$, Mário Fonseca Paulino ${ }^{3}$, Sebastião de Campos Valadares Filho ${ }^{3}$, Pedro Veiga Rodrigues Paulino ${ }^{3}$, Marlos Oliveira Porto ${ }^{2}$, Victor Rezende Moreira Couto ${ }^{2}$}

\footnotetext{
1 Pesquisa parcialmente financiada pelo CNPq e pela FAPEMIG.

2 Pós-graduação em Zootecnia - UFV, Viçosa - MG.

${ }^{3}$ Departamento de Zootecnia - UFV, Viçosa - MG. Pesquisador do INCT-CA.
}

RESUMO - Objetivou-se determinar as exigências de energia de bovinos de corte em pastagem de Brachiaria decumbens com suplementação. Foram utilizados 28 novilhos anelorados, não-castrados, com 7 meses de idade e 180 kg de peso vivo inicial. Oito animais foram abatidos em diferentes faixas de peso e serviram como referência. Para determinação das exigências líquidas para ganho de peso, foi construída uma equação de regressão entre o log da energia retida (ER) e o log do ganho de peso de corpo vazio (GPCVZ). As exigências de energia líquida para mantença (ELm) foram estimadas por meio do log da produção de calor (PC) em função do consumo de energia metabolizável (CEM). As eficiências de utilização da energia metabolizável para mantença $(\mathrm{km})$ foram estimadas pela relação entre os teores de ELm e a EM da dieta e a eficiência de utilização da energia para ganho de peso (kg) foi estimada como o coeficiente da regressão linear entre a energia retida e o consumo de energia metabolizável. As exigências de ELm de bovinos anelorados sob pastejo foram de 82,4 kcal/PCVZ0,75/dia ou 76,12 kcal/PV0,75/dia. Animais zebuínos não-castrados sob pastejo apresentam exigências líquidas de mantença 5\% superiores às de zebuínos em confinamento. As exigências diárias de EMm foram de 149,76 kcal/PCVZ ${ }^{0,75}$ e a eficiência de utilização da energia metabolizável para mantença $\left(\mathrm{k}_{\mathrm{m}}\right)$ de animais anelorados sob pastejo foi de $55 \%$ e para ganho $\left(\mathrm{k}_{\mathrm{g}}\right)$, de $29 \%$.

Palavras-chave: energia, exigências nutricionais, suplementação, suplementos múltiplos

\section{Body composition and energy requirements of supplemented grazing beef cattle}

\begin{abstract}
The objective in this trial was to estimate the energy requirements of supplemented Zebu bulls grazing Brachiaria decumbens paddocks. Twenty eight intact males, seven months old and initial body weight $180 \mathrm{~kg}$ were used. Eight animals were slaughtered as reference, in different weight ranges. The net energy requirements for weight gain were obtained by regressing the log of the retained energy (RE) on the log of empty body weight (EBW). The net energy requirements for maintenance (NEm) were obtained from regression of the log of the heat production (HP) on the metabolizable energy intake (MEI). The efficiency of metabolizable energy use for maintenance (km) was calculated as the ratio of net energy requirements for maintenance to metabolizable energy for maintenance (MEm) and the slope of the linear regression of retained energy on metabolizable energy intake was considered as an estimate of the efficiency of using metabolizable energy for weight gain $(\mathrm{kg})$. The net energy requirements for maintenance of Zebu bulls, under pasture, was $82.4 \mathrm{kcal} / \mathrm{EBW}^{0.75} / \mathrm{day}$ or $76.12 \mathrm{kcal} / \mathrm{BW}^{0.75} / \mathrm{day}$. Thus, grazing Zebu bulls have about $5 \%$ greater net energy requirements for maintenance than feedlot Zebu bulls. The daily requirements of metabolizable energy was $149.76 \mathrm{kcal} / \mathrm{EBW}^{0.75}$ and the efficiency of metabolizable energy used for maintenance $\left(\mathrm{k}_{\mathrm{m}}\right)$ of Zebu bulls under pasture was $55 \%$ and for gain $\left(\mathrm{k}_{\mathrm{g}}\right) 29 \%$.
\end{abstract}

Key Words: energy, multiple supplements, nutrient requirements, supplementation

\section{Introdução}

O corpo do animal é composto basicamente de água, proteína, gordura e minerais, em proporções que variam de acordo com a raça, a idade, a velocidade de crescimento, a classe sexual e o plano nutricional, entre outros fatores
(NRC, 2000). Embora o conteúdo corporal de proteína e gordura aumente com o peso do animal, o percentual de proteína reduz, enquanto os teores de gordura e energia tendem a aumentar (Boin, 1995). Como consequência, as exigências de energia aumentam com o peso vivo e as de proteína decrescem concomitantemente. 
Segundo Paulino et al. (1999), o valor energético do ganho de peso vivo depende da proporção de gordura e proteína depositadas no corpo. Como essas proporções mudam com o peso vivo e o estádio de maturidade, os valores de energia do ganho também mudam. Conforme descrito por Veloso et al. (2002), o verdadeiro determinante da composição do ganho de peso não é o peso corporal absoluto, mas o peso relativo ao peso à maturidade do animal, uma vez que o sexo influencia na composição corporal.

De acordo com o NRC (1984), os requerimentos de energia para mantença correspondem à quantidade de energia dietética que não resultará em ganhos ou perdas de energia corporal. Em estudos de bioenergética, Lofgreen \& Garrett (1968) estimaram as exigências líquidas de mantença em $77 \mathrm{kcal} / \mathrm{PV}^{0,75}$, valor adotado pelo NRC (2000). Esse valor refere-se a animais estabulados, sem estresse e com atividade normal mínima, utilizando somente animais taurinos.

Ainda segundo o NRC (2000), as raças zebuínas, nessas mesmas condições, requerem cerca de $10 \%$ menos energia para mantença que as taurinas, enquanto as raças mestiças têm exigências intermediárias. Essa menor exigência de mantença sugere que animais zebuínos utilizam com maior eficiência a energia metabolizável em relação aos mestiços, o que pode estar relacionado à menor atividade metabólica desses animais. Outros fatores podem influenciar nas exigências líquidas de energia de mantença, entre eles, a raça, idade, classe sexual, o nível de produção, o plano nutricional (Koong et al., 1985; NRC, 2000) e as atividades relacionadas ao pastejo.

Objetivou-se determinar a composição corporal e as exigências de energia de bovinos anelorados em pastagem de Brachiaria decumbens Stapf. suplementada com concentrado.

\section{Material e Métodos}

O experimento foi conduzido no no setor de Bovinocultura de Corte da Universidade Federal de Viçosa, entre os dias 4/7/2005 e 6/4/2006.

Foram utilizados 28 novilhos anelorados, nãocastrados, com 7 meses de idade e $180 \mathrm{~kg}$ de peso vivo inicial $(s=48,09)$, abatidos conforme protocolos de abate, dividido em quatro etapas.

Após o início do experimento, dia 14/7/2005, em plena estação seca, foram abatidos dois animais, com 7 meses de idade e peso médio de $180 \mathrm{~kg}$. No segundo abate, realizado no dia 10/10/2005, no início da fase de transição seca-águas, foram abatidos três animais, com peso médio de $180 \mathrm{~kg}$, em virtude da presença de um animal muito leve (145 kg e

8 meses de idade). Os outros dois animais encontravam-se com 205 e $180 \mathrm{~kg}$ e 9 meses de idade.

No terceiro abate, realizado no dia 10/1/2006 em pleno período das águas, foram abatidos outros três animais, com 15 meses de idade e $305 \mathrm{~kg}$ de peso vivo.

Durante os abates, todos os constituintes do corpo (órgãos, vísceras, sangue, couro, cabeça, membros) foram pesados e amostrados para determinação do peso de corpo vazio (PCVZ) e da composição corporal dos animais nas diferentes faixas de peso.

Os dados referentes ao abate inicial e intermediários foram utilizados para estimativa da composição corporal inicial dos 20 animais mantidos no experimento.

Os 20 animais restantes apresentavam 14 meses de idade e $316 \mathrm{~kg}$ ( $\mathrm{s}=59,74)$ e foram divididos em cinco lotes de quatro animais, segundo delineamento inteiramente casualizado. Cada lote recebeu um dos cinco tratamentos: mantença; mistura mineral; e suplemento, na proporção de 0,75; 1,50 e 2,25 kg/animal/dia e com 33\% de proteína bruta (Tabela 1). Todos os animais receberam, de forma irrestrita, mistura mineral.

Os quatro animais alocados no grupo em mantença foram manejados de forma a manter nível mínimo de perda ou ganho de peso. A permanência desses animais no pasto foi controlada: os animais foram conduzidos ao pastejo por 4 horas e posteriormente foram presos em área cercada (0,4 ha), sem forragem e com acesso apenas a água.

Tabela 1 - Composição percentual do suplemento, com base na matéria natural, e composição bromatológica do suplemento e do pasto (\% MS)

\begin{tabular}{lc}
\hline Ingrediente & $\%$ no suplemento \\
\hline Uréia/sulfato de amônia (9:1) & 2,50 \\
Milho & 31,00 \\
Farelo de soja & 16,50 \\
Farelo de algodão & 25,00 \\
Farelo de trigo & 25,00
\end{tabular}

Composição bromatológica

Item Suplemento B. decumbens
(extrusa esofágica)

Matéria seca (\%)

Matéria orgânica (\%MS)

Proteína bruta (\%MS)

Fibra em detergente neutro (\%MS)

Extrato etéreo (\%MS)

Carboidratos não-fibrosos (\%MS)

Carboidratos totais (\%MS)

Lignina (\%MS)

NIDA $^{3}$

NIDN $^{3}$

NIDN - nitrogênio indigestível em detergente neutro (\% do nitrogênio total); NIDA - nitrogênio indigestível em detergente ácido (\% do nitrogênio total). 
A área experimental destinada aos animais foi constituída de cinco piquetes de 2,0 ha, formados com Brachiaria decumbens Stapf., providos de bebedouros e comedouros cobertos. Visando reduzir a influência da variação na disponibilidade de matéria seca de pasto, os animais foram mantidos em cada piquete por sete dias e, após este período, procedeu-se ao rodízio entre os piquetes.

Todos os animais foram submetidos a um ensaio de digestão a pasto durante dez dias (os sete primeiros para adaptação dos animais e à estabilização do fluxo dos indicadores), conforme descrito por Titgemeyer et al. (2001). Para avaliar a composição bromatológica da forragem consumida pelos animais, foram utilizados cinco animais fistulados no esôfago, que, após jejum alimentar e hídrico de 16 horas, foram conduzidos aos piquetes para as coletas de extrusa, realizadas às $7 \mathrm{~h}$ do quinto dia do ensaio de digestão, utilizando-se bolsas coletoras com fundo telado, adaptadas em torno da fístula esofágica. Após 40 minutos de pastejo, as bolsas eram retiradas e as amostras pesadas.

A excreção de MS fecal foi estimada utilizando-se o indicador externo óxido crômico, segundo recomendações de Smith \& Reid (1955), aplicado em dose única diária (10 g/animal) acondicionado em cartucho de papel e introduzido por meio de um aplicador diretamente no esôfago dos animais durante nove dias consecutivos. Após sete dias de adaptação, foram coletadas amostras de fezes dos animais no oitavo (16 h), nono (12 h) e décimo (8 h) dias. O cálculo da excreção de matéria seca fecal (EF) foi realizado com base na razão entre a quantidade de indicador fornecido e sua concentração nas fezes, segundo a equação:

$$
\mathrm{EF}=(\mathrm{CrFo} / \mathrm{CrFe}) \times 100
$$

em que: $\mathrm{CrFo}=$ quantidade de cromo fornecida (g); $\mathrm{CrFe}=$ concentração de cromo nas fezes (\%).

O consumo voluntário de matéria seca (CMS) foi estimado pela relação entre a excreção de MS fecal e a indigestibilidade da dieta, a partir do indicador interno FDA indigestível (FDAi), obtida após 264 horas de incubação in situ (Casali et al., 2008), por meio da equação:

$\mathrm{CMS}=\{[(\mathrm{EF} \times \mathrm{FDAiFe})-\mathrm{FDAiS}] / \mathrm{FDAiFOR}\}+\mathrm{CMSS}$ em que: FDAiFe = FDAi nas fezes $(\mathrm{kg} / \mathrm{kg})$; FDAiS = FDAi no suplemento (kg/dia); FDAiFOR = concentração de FDAi na forragem $(\mathrm{kg} / \mathrm{kg})$; e CMSS = consumo de MS de suplemento ( $\mathrm{kg} / \mathrm{dia})$.

O consumo individual de suplemento (CMSs) foi determinado utilizando-se o dióxido de titânio (10 g/animal) misturado ao suplemento imediatamente antes do fornecimento, segundo procedimento descrito por Valadares Filho et al. (2006b), seguindo mesmo esquema de coletas de fezes descrito para o oxido crômico, pela equação:

$$
\mathrm{CMSs}=\left(\mathrm{EF} \times \mathrm{TiO}_{2} \mathrm{Fe}\right) / \mathrm{TiO}_{2} \mathrm{~S}
$$

em que: $\mathrm{TiO}_{2} \mathrm{Fe}$ e $\mathrm{TiO}_{2} \mathrm{~S}=$ concentração de dióxido de titânio nas fezes e no suplemento, respectivamente.

Após a coleta, as amostras de extrusa e fezes foram secas em estufa com ventilação forçada a $65^{\circ} \mathrm{C}$, por 72 horas, processadas em moinho tipo Willey com peneira de $1,0 \mathrm{~mm}$ e posteriormente submetidas às análises laboratoriais, de acordo com técnicas descritas por Silva \& Queiroz (2002), com exceção das determinações de FDN e FDA, que seguiram os métodos descritos por Mertens (2002) e Van Soest \& Robertson (1985). A partir dos consumos de matéria seca e das excreções fecais, foi possível calcular a digestibilidade dos nutrientes e estimar os consumos de energia metabolizável a partir dos teores de NDT das dietas.

O último abate foi realizado nos dias 27/3, 29/3, 3/4 e 5/4/2006, de forma escalonada, após 76, 78, 83 e 85 dias, com o abate de cinco animais por vez, um de cada tratamento. No momento do abate, os animais estavam, em média, com 17 meses de idade e $378 \mathrm{~kg}(\mathrm{~s}=57,62)$. Antes do abate, todos os animais foram submetidos a jejum de 16 horas para obtenção do peso vivo em jejum.

Após o abate, o trato gastrintestinal de cada animal foi pesado, esvaziado e lavado e seu peso somado ao dos órgãos e demais partes do corpo (carcaça, cabeça, couro, cauda, pés e sangue) para determinação do peso de corpo vazio (PCVZ). A relação entre o PCVZ e o peso vivo (PV) dos animais, em cada abate, foi utilizada para estimativa do PCVZ dos animais mantidos no experimento. Dentro de cada tratamento, foram sorteados dois animais, dos quais foram retiradas amostras da cabeça e de um membro anterior e outro posterior para separação física de tecido mole, ossos e couro.

As amostras de sangue foram coletadas imediatamente após a secção da veia jugular dos animais, acondicionadas em recipiente de vidro e deixadas em estufa com ventilação forçada a $60^{\circ} \mathrm{C}$ por 72 horas. As amostras de carne industrial, fígado, coração, rins, baço, pulmões, língua, rúmen, retículo, omaso, abomaso, intestino delgado, intestino grosso, mesentério, gordura interna, aparas e cauda foram agrupadas, processadas e homogeneizadas integralmente em um Cutter de 65 litros, de onde foi retirada uma amostra que representou os órgãos e vísceras.

A carcaça de cada animal foi dividida em duas metades, as quais foram pesadas e resfriadas em câmara fria a $-2,5^{\circ} \mathrm{C}$ por aproximadamente 18 horas. Decorrido esse tempo, as carcaças direitas de dez animais, dois por tratamento, foram retiradas da câmara fria e totalmente dissecadas, procedendo-se à separação em músculos, gordura e ossos, 
que foram posteriormente pesados. A composição corporal dos outros dez animais foi estimada por meio dos percentuais de músculo, gordura e ossos das carcaças dissecadas.

O tecido muscular e o tecido adiposo foram moídos e o tecido ósseo serrado em partes menores. Foi retirada uma amostra representativa de cada componente para determi-nação direta dos teores de proteína e gordura da carcaça.

Após a moagem, as amostras frescas foram processadas conforme procedimento descrito por Paulino et al. (2004), para obtenção da matéria seca gordurosa (MSG) e da matéria seca pré-desengordurada (MSD). Em seguida, as amostras foram processadas em moinho de bola para posteriores quantificações do nitrogênio total e extrato etéreo, conforme recomendações de Silva \& Queiroz (2002). O teor de proteína foi obtido pelo produto entre o teor de nitrogênio total e o fator 5,88 conforme sugerido por Baldwin (1995).

A gordura removida no pré-desengorduramento foi calculada pela diferença entre a matéria seca gordurosa e a matéria seca pré-desengordurada, cujo resultado foi somado ao obtido para o extrato etéreo residual na matéria seca pré-desengordurada, para quantificação do teor total de gordura.

Os conteúdos de proteína e gordura no corpo vazio foram determinados de acordo com suas concentrações percentuais nas amostras dos constituintes separados da carcaça e nas amostras de órgãos e vísceras, couro, sangue, cabeça e membros.

O conteúdo de energia corporal foi obtido a partir dos teores de proteína e gordura retidos no corpo vazio e seus equivalentes calóricos, conforme equação proposta pelo $\operatorname{ARC}(1980):$

$$
\mathrm{CE}=5,6405 \mathrm{X}+9,3929 \mathrm{Y}
$$

em que: $\mathrm{CE}=$ conteúdo energético (Mcal); $\mathrm{X}=$ proteína corporal (kg); Y = gordura corporal (kg).

Os conteúdos de gordura e energia retidos no corpo dos animais foram estimados por meio da regressão do logaritmo do conteúdo de gordura ou energia em função do logaritmo do PCVZ, segundo o ARC (1980), conforme o seguinte modelo:

$$
\mathrm{Y}=\mathrm{a}+\mathrm{bX}+\mathrm{e}
$$

em que: $\mathrm{Y}=$ logaritmo do conteúdo total de gordura $(\mathrm{kg})$ ou energia (Mcal) retido no corpo vazio; $\mathrm{a}=$ intercepto; $\mathrm{b}=$ coeficiente de regressão do logaritmo do conteúdo de gordura ou energia, em função do logaritmo do PCVZ; $\mathrm{X}=$ logaritmo do PCVZ; e = erro aleatório.

Derivando as equações de predição do conteúdo corporal de gordura ou energia em função do logaritmo do
PCVZ, obtiveram-se as exigências líquidas de energia, por kg de ganho de PCVZ (GPCVZ), e os conteúdos de gordura, por kg de GPCVZ, a partir de equações do tipo:

$$
\mathrm{Y}^{\prime}=\text { b. } 10^{\mathrm{a}} \cdot \mathrm{X}^{\mathrm{b}-1}
$$

em que: $\mathrm{Y}^{\prime}=$ conteúdo de gordura no ganho ou exigências líquidas de energia para ganho; a e b = intercepto e coeficiente de regressão das equações de predição dos conteúdos corporais de gordura ou das exigências líquidas de energia; $\mathrm{X}=$ PCVZ $(\mathrm{kg})$.

Para a conversão do peso vivo em PCVZ, dentro do intervalo de pesos incluído no trabalho, calculou-se a relação entre o PCVZ e o peso vivo dos 28 animais mantidos no experimento. Para conversão das exigências para GPCVZ em exigências para ganho de PV, utilizou-se o fator 0,930 obtido a partir dos dados experimentais.

As exigências líquidas para ganho de peso (ELg) de animais de diferentes ganhos de peso de corpo vazio e de diferentes faixas de peso vazio foram estimadas por meio de uma relação entre a energia retida (ER) e o PCVZ metabólico e do GPCVZ, segundo NRC (2000):

$$
\mathrm{ER}(\mathrm{Mcal} / \mathrm{dia})=10^{\mathrm{a}} \times \mathrm{PCVZ}^{0,75} \times \mathrm{GPCVZ}^{\mathrm{b}}
$$

A concentração de energia digestível (ED) da dieta foi obtida pela equação proposta pelo NRC (2000): $\mathrm{ED}(\mathrm{Mcal} / \mathrm{kg} \mathrm{MS})=5,6 \times \mathrm{PBD}+9,4 \times \mathrm{EED}+4,2 \times \mathrm{FDND}+$

\section{$4,2 \times$ CNFD.}

A concentração de energia metabolizável (EM) foi considerada como 82\% da energia digestível (NRC, 2000).

As exigências de energia metabolizável para mantença foram estimadas a partir da relação entre o logaritmo da produção de calor (PC, kcal/PCVZ ${ }^{0,75} / \mathrm{dia}$ ) e o consumo de energia metabolizável (CEM, kcal/PCVZ $0,75 /$ dia). O consumo de energia metabolizável para mantença (EMm) foi estimado considerando o ponto de equilíbrio no qual a produção de calor foi igual ao consumo de energia metabolizável, segundo a técnica utilizada por Garrett (1980).

As exigências líquidas de energia para mantença (ELm) foram estimadas como o anti-logarítmo do intercepto da equação obtida pela regressão linear entre o logaritmo da produção de calor e o consumo de energia metabolizável, segundo Lofgreen \& Garret (1968).

As eficiências de utilização da energia metabolizável para mantença $(\mathrm{km})$ foram estimadas a partir da relação entre os teores de energia líquida para mantença e a energia metabolizável da dieta, segundo Garret (1980), e a eficiência de utilização da energia metabolizável para ganho de peso (kg) foi estimada como a inclinação da regressão linear entre a energia retida e o consumo de energia metabolizável, segundo o NRC (2000) e Ferrel \& Jenkins (1998). 
As exigências de energia metabolizável para mantença e ganho foram obtidas pelas relações entre as exigências líquidas e as respectivas eficiências de utilização, estimadas segundo Garret (1980). As exigências de NDT foram calculadas dividindo-se as exigências de energia metabolizável por 0,82, obtendo-se as exigências de energia digestível (ED) e, posteriormente, dividindo-as por 4,409.

As exigências para ganho de $1 \mathrm{~kg}$ de PCVZ foram multiplicadas pelo fator 0,93 para obtenção das exigências líquidas para ganho de $1 \mathrm{~kg}$ de $\mathrm{PV}$, conforme relação obtida entre o ganho de peso de corpo vazio e o ganho de peso vivo dos animais.

\section{Resultados e Discussão}

A relação obtida para a estimativa do PCVZ a partir do PV dos animais foi: $\mathrm{PCVZ}=\mathrm{PV} \times 0,8997$, valor próximo àquele recomendado pelo NRC (2000), de 0,891, e Valadares Filho et al. (2006a), de 0,8960, embora essas relações tenham sido obtidas para animais em confinamento. Em comparação às relações disponíveis para animais em pastejo, os dados deste trabalho são numericamente superiores aos encontrados por Zervoudakis et al. (2002), Fregadolli (2005) e Moraes (2006), de 0,8575; 0,8746 e 0,8877 , respectivamente, para animais em pastejo.

Para conversão das exigências para ganho de PCVZ (GPCVZ) em exigências para ganho de peso vivo (GPV), foi obtida a seguinte relação: GPCVZ = 0,930 $\times$ GPV, semelhante à recomendada por Valadares Filho et al. (2006a), de 0,933.

Os conteúdos corporais de gordura (de 11,86 para $37,38 \mathrm{~kg}$, um aumento de 215,17\%) e energia (de 256,66 para $732,77 \mathrm{Mcal}$ ou 185,50\%) aumentaram com o aumento do peso vivo dos animais de 150 para $400 \mathrm{~kg}$ (Tabela 2). Da mesma forma, as concentrações de gordura, em $\mathrm{g} / \mathrm{kg}$ de PCVZ, e de energia, em Mcal/kg de PCVZ, aumentaram de acordo com o peso corporal (Tabela 3).

Os teores iniciais de gordura e energia no corpo dos animais foram muito próximos aos descritos na literatura. Paulino et al. (1999), trabalhando com novilhos de quatro raças zebuínas, não-castrados, com 24 meses de idade e
Tabela 2 - Parâmetros das equações de regressão do logaritmo dos conteúdos de gordura (kg) e energia (Mcal) no corpo vazio em função do logaritmo do peso do corpo vazio (kg) dos animais

\begin{tabular}{lccc}
\hline Componente & \multicolumn{3}{c}{ Parâmetro } \\
\cline { 2 - 4 } & Intercepto (a) & Coeficiente (b) & $\mathrm{r}^{2}$ \\
\hline Gordura (kg) & $-1,4201$ & 1,1708 & 92,83 \\
Energia (Mcal) & 0,1309 & 1,0696 & 98,51 \\
\hline
\end{tabular}

$\mathrm{PCVZ}=\mathrm{PV} \times 0,8997$.

366 kg, observaram aumentos nos conteúdos corporais de gordura (de 28,10 para 59,20 kg) e energia (de 508,61 para 899,18 Mcal) com o aumento do PV dos animais de 300 para $400 \mathrm{~kg}$. Véras et al. (2001), trabalhando com novilhos Nelore, não castrados, com idade e peso médios iniciais de 20 meses e $330 \mathrm{~kg}$, também observaram conteúdos corporais de gordura variando de 35,61 a 61,71 kg e de energia variando de 612,61 a 955,99 Mcal com o aumento do peso vivo de 300 para $400 \mathrm{~kg}$. Contudo, mesmo seguindo as tendências normais de aumento nos teores de energia com o aumento do peso vivo, esses aumentos foram de menor magnitude em relação aos descritos na maioria dos trabalhos nacionais. Esse comportamento pode estar relacionado ao fato de esses trabalhos envolverem animais confinados, com grande aporte energético nas dietas e altas taxas de ganho de peso. Além disso, os animais apresentavam grande diferença de idade em relação aos deste estudo (14 e 10 meses a mais, respectivamente). Essa grande diferença de idade, juntamente com a maior densidade energética da dieta e a condição de confinamento, com mínimo de atividade física, pode explicar as maiores deposições de gordura e de energia no corpo daqueles animais.

Seguindo a linha de pesquisa que visa ao abate precoce dos animais, não considerando o grau de acabamento, procedeu-se ao abate desses animais aos 17 meses de idade. Esse fato, entre outros, pode explicar o baixo teor de gordura encontrado na carcaça desses animais, além dos menores requisitos energéticos para ganho de peso, indicando que os mesmos ainda se encontravam em fase de

Tabela 3 - Estimativa dos conteúdos corporais de gordura e energia em bovinos anelorados sob suplementação em pastejo

\begin{tabular}{lcccc}
\hline Peso vivo $(\mathrm{kg})$ & Gordura $(\mathrm{kg})$ & Gordura $(\mathrm{g} / \mathrm{kg}$ PCVZ) & Energia (Mcal) & Energia $($ Mcal/kg PCVZ) \\
\hline 150 & 11,86 & 87,85 & 256,66 & 1,90 \\
200 & 16,60 & 92,27 & 349,13 & 1,94 \\
250 & 21,56 & 95,86 & 443,24 & 1,97 \\
300 & 26,69 & 98,89 & 538,68 & 2,00 \\
350 & 31,97 & 101,53 & 635,24 & 2,02 \\
400 & 37,38 & 103,87 & 732,77 & 2,04 \\
\hline
\end{tabular}

$\mathrm{PCVZ}=\mathrm{PV} \times 0,8997$ 
crescimento e, portanto, com deposição mais acelerada de proteína em detrimento da gordura, fato que ocorre normalmente antes da maturidade fisiológica.

A menor deposição de gordura no corpo, seguida por maior concentração proteica do ganho de peso em animais não castrados, é explicada pela síntese e secreção dos hormônios androgênicos, substâncias esteroides com ação anabólica pronunciada no organismo animal (Phillips, 2001; Guiroy et al., 2002).

Relacionando o logaritmo da produção de calor (PC) em função do consumo de energia metabolizável (CEM) foi obtida a equação: $\log P C=1,9160+0,0017$ CEM, $\mathrm{r}^{2}=0,97$, cujo anti-log do intercepto indicou o valor de $82,4 \mathrm{kcal} /$ $\mathrm{PCVZ}^{0,75}$ /dia como exigência de energia líquida de mantença (ELm) dos animais. A partir desta equação, obteve-se o consumo de energia metabolizável (CEM) no equilíbrio, ou seja, no ponto em que a produção de calor foi igual ao CEM, obtendo-se o valor de 149,76 kcal/PCVZ ${ }^{0,75 / d i a . ~}$

A energia líquida de mantença (ELm) também foi obtida como o coeficiente "a" da equação de regressão exponencial entre a produção de calor e o CEM, segundo Ferrel \& Jenkins (1998): $P C=82,405 \mathrm{e}^{0,0039 C E M}, \mathrm{R}^{2}=0,97$. Esse valor foi $5 \%$ superior àquele sugerido por Valadares Filho et al. (2006a) como exigência de energia líquida para mantença de animais zebuínos no Brasil, que foi de 78,5 kcal/PCVZ ${ }^{0,75}$. Essa diferença pode estar relacionada ao maior esforço físico ao qual são submetidos os animais durante o pastejo.

Calculando-se a ELm em função do PV, para os dados deste experimento, obteve-se o valor de 76,12 kcal/PV0,75/dia, aproximadamente $5 \%$ superior ao recomendado por Valadares Filho et al. (2006a) de 72,3 e 10\% superior ao recomendado pelo NRC (2000) para zebuínos, $69 \mathrm{kcal} / \mathrm{PV}^{0,75} / \mathrm{dia}$.

As exigências de energia metabolizável e energia digestível e nutrientes digestíveis totais aumentaram de acordo com o peso corporal, seguindo tendência semelhante à observada para as exigências líquidas de energia para mantença (Tabela 4).
Assim, considerando-se a km obtida de 0,55(ELm/EMm) e o valor de 76,12 kcal/PV ${ }^{0,75}$ como requisito líquido de energia para mantença, as exigências de energia metabolizável para mantença seriam de $138,4 \mathrm{kcal} / \mathrm{PV}^{0,75}$, a de energia digestível de 168,78 kcal/PV ${ }^{0,75}$ e a de NDT de 38,28 g/PV0,75.

A equação de regressão obtida para descrever a relação entre a retenção diária de energia (ER), em Mcal/dia, e o ganho diário de PCVZ (GPCVZ) a determinado PCVZ foi:

$\mathrm{ER}=0,0416 \times \mathrm{PCVZ}^{0,75} \times \mathrm{GPCVZ}^{1,1499}\left(\mathrm{R}^{2}=0,81\right)$.

Considerando um bovino castrado de $400 \mathrm{~kg}$ de $\mathrm{PV}$ e com ganho diário de peso vivo em jejum (GDPVJ) de 1,0 kg, pode-se calcular, a partir desta equação, que a energia retida é de 3,16 Mcal/dia. Se esse mesmo cálculo for feito a partir da equação preconizada pelo BR-Corte (Valadares Filho et al., 2006a) para zebuíno não-castrado: $\mathrm{ER}=0,0529$ $\times \mathrm{PCVZ}^{0,75} \times \mathrm{GPCVZ}^{1,0996}$, a energia retida será igual a 4,04 Mcal/dia, cerca de 21,8\% maior. Essa diferença está relacionada ao maior consumo de energia metabolizável dos animais confinados em relação aos mantidos em pastejo. Outro aspecto importante é a maior eficiência de utilização da energia para ganho de peso nos animais confinados, em comparação àqueles mantidos sob pastejo, o que pode estar relacionado ao menor incremento calórico da digestão de dietas ricas em grãos, se comparadas a dietas ricas em volumosos, e à menor atividade física dos animais em confinamento.

As exigências líquidas de energia para ganho 1,0 kg de PV determinadas neste trabalho (Tabela 5) foram menores que aquelas descritas na literatura, possivelmente em decorrência do menor teor de gordura no ganho de peso dos animais utilizados neste estudo. $\mathrm{O}$ valor encontrado neste trabalho, no entanto, foi bem próximo ao descrito por Fregadolli (2005), que, trabalhando com animais em pastejo recebendo suplemento, pertencentes a vários grupos genéticos, observou exigências líquidas de energia para ganho de peso de um animal de $400 \mathrm{~kg}$ de PV ganhando $1,0 \mathrm{~kg} / \mathrm{dia}$, o valor de 3,13 Mcal/dia.

Tabela 4 - Exigências diárias de energia metabolizável (EM) e energia digestível (ED), expressas em Mcal/dia, e requisitos de NDT (kg/dia) para mantença de bovinos anelorados estimadas em relação ao peso vivo

\begin{tabular}{|c|c|c|c|c|c|c|}
\hline & \multicolumn{6}{|c|}{ Peso vivo (kg) } \\
\hline & 150 & 200 & 250 & 300 & 350 & 400 \\
\hline EMm (Mcal/dia) & 5,930 & 7,358 & 8,698 & 9,973 & 11,195 & 12,374 \\
\hline EDm (Mcal/dia) & 7,231 & 8,973 & 10,607 & 12,162 & 13,652 & 15,090 \\
\hline EDg (Mcal/GPCVZ) & 6,907 & 8,570 & 10,131 & 11,616 & 13,039 & 14,413 \\
\hline NDTm (kg/dia) & 1,640 & 2,035 & 2,406 & 2,758 & 3,096 & 3,423 \\
\hline
\end{tabular}

$\mathrm{PCVZ}=\mathrm{PV} \times 0,8997$ 
Tabela 5 - Exigências nutricionais de energia para animais anelorados estimadas em relação ao peso vivo (PV) e ao ganho médio diário (GMD)

\begin{tabular}{|c|c|c|c|c|c|c|c|}
\hline & & \multicolumn{6}{|c|}{ Peso vivo (kg) } \\
\hline & & 150 & 200 & 250 & 300 & 350 & 400 \\
\hline & $E L m^{a}$ & 3,26 & 4,05 & 4,78 & 5,49 & 6,16 & 6,81 \\
\hline & EMm & 5,93 & 7,36 & 8,70 & 9,97 & 11,20 & 12,37 \\
\hline \multicolumn{8}{|c|}{$\begin{array}{l}\text { Exigências para ganho } \\
\text { EL para ganho, Mcal/dia }\end{array}$} \\
\hline \multirow[t]{2}{*}{ Ganho médio diário } & $0,50 \mathrm{~kg} / \mathrm{dia}$ & 0,68 & 0,85 & 1,00 & 1,15 & 1,29 & 1,43 \\
\hline & $1,00 \mathrm{~kg} / \mathrm{dia}$ & 1,52 & 1,88 & 2,23 & 2,55 & 2,87 & 3,17 \\
\hline \multicolumn{8}{|l|}{$\begin{array}{l}\text { Exigências totais } \\
\text { EM }^{\text {b }} \text {, Mcal/dia }\end{array}$} \\
\hline \multirow[t]{2}{*}{ Ganho médio diário } & $0,50 \mathrm{~kg} / \mathrm{dia}$ & 8,28 & 10,27 & 12,14 & 13,92 & 15,63 & 17,27 \\
\hline & $1,00 \mathrm{~kg} / \mathrm{dia}$ & 11,14 & 13,82 & 16,34 & 18,74 & 21,03 & 23,25 \\
\hline \multicolumn{8}{|l|}{ NDT, kg/dia } \\
\hline \multirow[t]{2}{*}{ Ganho médio diário } & 0,50 kg/dia & 2,29 & 2,84 & 3,36 & 3,85 & 4,32 & 4,78 \\
\hline & $1,00 \mathrm{~kg} / \mathrm{dia}$ & 3,08 & 3,82 & 4,52 & 5,18 & 5,82 & 6,43 \\
\hline
\end{tabular}

a $76,12 \mathrm{kcal} / \mathrm{kg} \mathrm{PV}^{0,75} ;{ }^{\mathrm{b}} \mathrm{km}=0,55$ e $\mathrm{kg}=0,29$.

\section{Conclusões}

As exigências diárias de energia líquida para mantença de bovinos anelorados sob pastejo são de $82,4 \mathrm{kcal} / \mathrm{PCVZ}^{0,75}$ ou 76,12 kcal/PV0,75. Recomenda-se estimar as exigências líquidas de energia para ganho de peso de bovinos anelorados sob pastejo pela equação: $\mathrm{ELg}=0,0416 \times \mathrm{PCVZ}^{0,75} \times$ GPCVZ1,1499 $\left(R^{2}=81,34\right)$. A eficiência de utilização da energia metabolizável para mantença $(\mathrm{km})$ de animais anelorados sob pastejo é de $55 \%$ e para ganho $\left(\mathrm{k}_{\mathrm{g}}\right)$, de $29 \%$.

\section{Literatura Citada}

AGRICULTURAL RESEARCH COUNCIL - ARC. The nutrient requirements of ruminants livestock. London: Commonwealth Agricultural Bureaux, 1980. 351p.

BALDWIN, R.L. Modeling ruminant digestion and metabolism. London: Chapman and Hall, 1995. 592p.

BOIN, C. Alguns dados sobre exigências de energia e proteína de zebuínos. In: SIMPÓSIO INTERNACIONAL SOBRE EXIGENCIAS NUTRICIONAIS DE RUMINANTES, 1995, Viçosa, MG. Anais... Viçosa, MG: Universidade Federal de Viçosa, 1995. p.457-465.

CASALI, A.O.; DETMANN, E.; VALADARES FILHO, S.C. et al. Influência do tempo de incubação e do tamanho de partículas sobre os teores de compostos indigestíveis em alimentos e fezes bovinas obtidos por procedimentos in situ. Revista Brasileira de Zootecnia, v.37, n.2, p.335-342, 2008.

FERRELL, C.L.; JENKINS, T.G. Body composition and energy utilization by steers of diverse genotypes fed a high-concentrate diet during the finishing period: II. Angus, Boran, Brahman, Hereford, and Tuli sires. Journal of Animal Science, v.76, p.647-657, 1998.

FREGADOLLI, F.L. Composição corporal e exigências nutricionais de novilhos de três grupos genéticos em pastejo. 2005. 85f. Tese (Doutorado em Zootecnia) Universidade Estadual Paulista, Faculdade de Ciências Agrárias e Veterinárias, 2005, Jaboticabal.

GARRETT, W.N. Factors influencing energetic efficiency of beef production. Journal of Animal Science, v.51, n.6, p.1434-1440, 1980.
GUIROY, P.J.; TEDESCHI, L.O.; FOX, D.G. et al. The effects of implant strategy on finished body weight of beef cattle. Journal of Animal Science, v.80, p.1791-1800, 2002.

KOONG, L.J.; FERREL, C.L.; NIENABER, J.A. Assessment of interrelationships among levels of intake and production, organ size and fasting heat production in growing animals. Journal of Nutrition, n.115, v.10, p.1383-1390, 1985.

LOFGREEN, G.P.; GARRETT, W.N.A. System for expressing net energy requeriments and feed values for growing and finishing beef cattle. Journal of Animal Science, v.27, n.3, p.793806, 1968.

MERTENS, D.R. Gravimetric determination of amylase treated neutral detergent fiber in feeds with refluxing in beakers or crucibles: collaborative study. Journal of AOAC International, v.85, n.6, p.1212-1240, 2002.

MORAES, E.H.B.K. Desempenho e exigências de energia, proteína e minerais de bovinos de corte em pastejo, submetidos a diferentes estratégias de suplementação. 2006. 151f. Tese (Doutorado em Zootecnia) - Universidade Federal de Viçosa, Viçosa, MG, 2006.

NATIONAL RESEARCH COUNCIL - NRC. Nutrient requirement of beef cattle. 6.ed. Washington, D.C.: National Academic Press, 1984. 90p.

NATIONAL RESEARCH COUNCIL - NRC. Nutrient requirements of beef cattle. 7.rev.ed. Washington, D.C.: National Academic Press, 2000. 242p.

PAULINO, M.F.; FONTES, C.A.A.; JORGE, A.M. et al. Composição corporal e exigências de energia e proteína para ganho de peso de bovinos de quatro raças zebuínas. Revista Brasileira de Zootecnia, v.28, n.3, p.627-633, 1999.

PAULINO, P.V.R; COSTA, M.A.L.; VALADARES FILHO, S.C. et al. Exigências nutricionais de zebuínos. Energia. Revista Brasileira de Zootecnia, v.33, n.3, p.781-791, 2004.

PHILLIPS, C.J.C. Principles of cattle nutrition. Cambridge: Cab International, 2001. 269p.

SILVA, D.J.; QUEIROZ, A.C. Análise de alimentos (métodos químicos e biológicos). 3.ed. Viçosa, MG: Universidade Federal de Viçosa, 2002. 235p.

SMITH, A.M.; REID, J.T. Use of chromic oxide as an indicator of fecal output for the purpose of determining the intake of a pasture herbage by grazing cows. Journal of Dairy Science, v.38, n.5, p.515-524, 1955.

TITGEMEYER, E.C.; ARMENDARIZ, C. K.; BINDEL, D.J. et al. Evaluation of titanium dioxide as a digestibility marker for cattle. Journal of Animal Science, v.79, p.1059-1063, 2001. 
VALADARES FILHO, S.C.; PAULINO, P.V.R.; DETMANN, E. et al. Exigências Nutricionais de Zebuínos no Brasil. I. Energia. In: VALADARES FILHO; S.C.; PAULINO; P.V.R.; MAGALHÃES; K.A. (Eds.). Exigências nutricionais de zebuínos e tabelas de composição de alimentos BR-Corte. 1.ed. Viçosa, MG: Suprema Gráfica Ltda., 2006a. p.57-73.

VALADARES FILHO, S.C.; MORAES, E.H.B.K.; DETMANN, E. et al. Perspectivas do uso de indicadores para estimar o consumo individual de bovinos alimentados em grupo. In: REUNIÃO ANUAL DA SOCIEDADE BRASILEIRA DE ZoOteCniA, 43., 2006, João Pessoa. Anais... João Pessoa: Sociedade Brasileira de Zootecnia, 2006b. p.291-322.

VAN SOEST, P.J.; ROBERTSON, J.B. Analysis of forages and fibrous foods. Ithaca: Cornell University, 1985. 202p.
VELOSO, C.M.; VALADARES FILHO, S.C.; GESUALDI JR., A. et al. Eficiência de utilização da energia metabolizável para mantença e ganho de peso e exigências de energia metabolizável e de nutrientes digestíveis totais de bovinos F1 Limousin x Nelore não castrados. Revista Brasileira de Zootecnia, v.31, n.3, p.1286-1293, 2002. VÉRAS, A.S.C.; VALADARES FILHO, S.C.; SILVA, J.F.C. et al. Eficiência de utilização da energia metabolizável para mantença e ganho de peso e exigências de energia metabolizável e de nutrientes digestíveis totais de bovinos Nelore, não-castrados. Revista Brasileira de Zootecnia, v.30, n.3, p.904-910, 2001. ZERVOUDAKIS, J.T.; PAULINO, M.F.; DETMANN, E. et al. Conteúdo corporal e exigências líquidas de proteína e energia de novilhos suplementados no período das águas. Revista Brasileira de Zootecnia, v.31, n.1, p.530-537, 2002. 